\title{
Efeito da Estirpe LT 516 de Lactobacillus acidophlilus como Probiótico para Bezerros ${ }^{1}$ \\ Antônio Hamilton Chaves ${ }^{2}$, José Fernando Coelho da Silva ${ }^{3}$, Oriel Fajardo de Campos ${ }^{4}$, Adão José Rezende Pinheiro ${ }^{5}$, Sebastião de Campos Valadares Filho ${ }^{3}$
}

\begin{abstract}
RESUMO - O objetivo deste trabalho foi verificar o efeito do fornecimento da estirpe LT 516 de Lactobacillus acidophilus, junto ao leite, sobre o desempenho de bezerros de rebanhos leiteiros, do nascimento aos 56 dias de idade. Trinta e seis bezerros recém-nascidos foram distribuídos em blocos ao acaso de acordo com o sexo, grau de sangue e peso ao nascer. O fornecimento diário de um concentrado com células viáveis (1,9 x $10^{10}$ UFC/anim) de Lactobacillus acidophilus (LT 516), do nascimento aos 56 dias de idade (Tratamento 1 ), o fornecimento diário do mesmo concentrado do nascimento aos 10 dias de idade (Tratamento 2) e o não-fornecimento de Lactobacillus acidophilus (Tratamento 3) foram estudados. Os animais foram alimentados com $4 \mathrm{~L}$ de leite integral/anim $\bullet$ e, a partir da segunda semana de idade, concentrado inicial e capim-elefante (Pennisetum purpureum Schum) picado, à vontade. Não houve diferenças entre tratamentos nos consumos e nas digestibilidades aparentes da matéria seca e proteína bruta, no ganho de peso, na contagem de hematócritos, hemoglobina, glóbulos vermelhos e hemoglobina globular média, na concentração de hemoglobina globular média, no volume globular médio e na contagem global de leucócitos, na capacidade absortiva do intestino (estimada pelo teste de xilose), no pH da digesta do intestino delgadoe no número de lactobacilos facultativos e coliformes totais nas fezes. O fornecimento de Lactobacillus acidophilus (LT 516) reduziu a ocorrência de diarréias, sem influir no odor e na consistência das fezes. Os animais que receberam probiótico nos primeiros 10 dias apresentaram maior número de lactobacilos facultativos no intestino delgado. O número de coliformes totais no intestino delgado foi maior nos animais controle e menor nos que receberam probiótico nos primeiros 56 dias.
\end{abstract}

Palavras-chave: bezerros, diarréia, Lactobacillus acidophilus, probiótico

\section{Effect of One Strain of Lactobacillus acidophilus (LT 516) as Probiotic for Calves}

ABSTRACT - The objective of this work was to verify the effect of the supply LT 516 strain of Lactobacillus acidophilus, adjoining to the milk, on dairy calves performance from birth to 56 days of age. Thirty-six newborn calves were allotted to a randomized blocks grouped by sex, breed and birth weight. The daily supply of a concentrate with viable cell (1,9 x $10^{10} \mathrm{UFC} / \mathrm{anim}$ ) of Lactobacillus acidophilus (LT 516 ), from birth to 56 days of age (Treatment 1); the daily supply of the same concentrate from birth to 10 days of age (Treatment 2 ) and no supply of Lactobacillus acidophilus (Treatment 3) were studied. Calves were fed $4 \mathrm{~L}$ of whole milk/anim•d, and from the second week of age, a starter concentrate and ad libitum chopped elephant grass (Pennisetum purpureum Schum). There were no differences among treatments on dry matter and crude protein intakes and apparent digestibility, weight gain, hematocrit, hemoglobin, red globules count, average globular hemoglobin, average globular hemoglobin concentration, average globular volume and leukocytes global count, on the absorptive capacity (estimated by the xylose test), calves intestinal digest $\mathrm{pH}$ and neither fecal facultative lactobacilli and total coliforms number. Lactobacillus acidophilus (LT 516) administration reduced diarrhea occurrence, without affecting feces odor and consistency. Calves fed probiotic for the first 10 days showed higher number of facultative lactobacilli in the small intestine. The number of total coliforms in the small intestine was higher in control calves, and lower in calves fed probiotic for the first 56 days of age.

Key Words: dairy calves, diarrhea, Lactobacillus acidophilus, probiotic

\section{Introdução}

Um dos principais objetivos dos produtores de leite é a redução nos índices de morbidez e mortalidade de bezerros. PENHA e D' APICE (1944) demonstraram a importância da diarréia dos bezerros como fator limitante na pecuária brasileira, especialmente em relação aos prejuízos acarretados pela morbidade e mortalidade, relativamente altas. TORRES (1959) relatou que a mortalidade dos bezerros, dependendo da região estudada e do manejo de cada propriedade, variou de 3,8 a 58\%. Segundo PIANTA (1993), no gado de leite criado de forma intensiva, a mortalidade varia, normalmente, entre 10 e 50\%. COSTA et al.

\footnotetext{
1 Parte do trabalho de Tese de Doutorado do primeiro autor, apresentada ao Departamento de Zootecnia da UFV, Viçosa, MG. Parcialmente financiado pelaFAPEMIG e EMBRAPA/CNPGL.

${ }^{2}$ Professor da Escola Agrotécnica Federal de Uberaba, Uberaba, MG.

${ }^{3}$ Professor do DZO, UFV, Viçosa, MG, Bolsistas do CNPq.

${ }^{4}$ Pesquisador da EMBRAPA/CNPGL, Coronel Pacheco, MG.

5 Professor do DTA, UFV, Viçosa, MG, Bolsista do CNPq.
} 
(1979), examinando 2733 bezerros lactentes, em Goiânia, observaram 224 casos de diarréia $(8,2 \%)$ e, na maioria, Escherichia coli e Salmonella sp estavam presentes. MADRUGA et al. (1982), estudando as doenças de bezerros de corte, no Mato Grosso do Sul, concluíram que o complexo mórbido mais freqüente foi o das diarréias (55\%). Estudos das enterites bacterianas nos bovinos recém-nascidos, na região de São Paulo, revelaram $15 \%$ de mortalidade de bezerros (VALENTE e AMARAL,1971) e 66,1\% na Zona da Mata de Minas Gerais (RIBEIRO et al., 1983).

O controle biológico, usando-se microrganismos que venham a competir com as bactérias entéricas causadoras de diarréias, poderá diminuir a morbidez e mortalidade dos bezerros. Este princípio fundamenta-se no uso de probióticos, produtos que contêm microrganismos adicionados diretamente ao alimento, contribuindo para o balanceamento microbiano intestinal. Revisões sobre o potencial benefício dos probióticos foram publicadas por SISSONS (1989) e VANBELLE et al. (1990).

Foi verificado que estirpes de Lactobacillus acidophilus isoladas de fezes de bezerros são mais efetivas como probiótico para esta espécie que as de outras origens, provavelmente devido a certa especificidade apresentada quanto ao hospedeiro (GILLILAND et al., 1980).

As bactérias da flora intestinal de animais domésticos têm importante papel na digestão e absorção dos nutrientes ingeridos pelo animal. O probiótico administrado pode permanecer no trato gastrointestinal, onde elimina ou inibe a proliferação de microrganismos nocivos e, ao mesmo tempo, facilita o crescimento de bactérias benéficas; desse modo, restaura e mantém o balanço normal da flora bacteriana intestinal. Esta normalização da flora intestinal é de grande valia na prevenção e no tratamento de diarréias e na regularização dos intestinos, restringindo a proliferação de muitos microrganismos patogênicos, como Escherichia coli, Salmonella sp e Clostridium perfringens. Alguns mecanismos de atuação têm sido investigados quanto ao modo com que as bactérias probióticas inibem a colonização do intestino por bactérias patogênicas. A adesão à parede intestinal é condição primordial para que a Escherichia coli produza enterotoxinas e induza diarréias; portanto, o ideal é que os probióticos, como o Lactobacillus acidophilus, venham a competir com estes coliformes pelos sítios de aderência na superfície intestinal.

O objetivo do presente trabalho foi avaliar os efeitos da presença do Lactobacillus acidophilus (LT 516) na dieta de bezerros de rebanhos leiteiros sobre consumo e digestibilidade de nutrientes, ganho de peso, incidência de diarréias, alguns parâmetros sangüíneos, a capacidade absortiva do intestino delgado, $\mathrm{pH}$ na digesta intestinal, número de lactobacilos facultativos e coliformes totais nas fezes e na digesta e mucosa do duodeno, jejuno e íleo.

\section{Material e Métodos}

O experimento foi conduzido nas dependências do Centro Nacional de Pesquisa de Gado de Leite, em Coronel Pacheco, Minas Gerais, em parceria com o Departamento de Zootecnia da Universidade Federal de Viçosa, no período de 17 de abril a 12 de agosto de 1995. Foram utilizados 36 bezerros, sendo 33 mestiços Holandês-Zebu e três da raça holandesa variedade preto e branco, do nascimento aos 56 dias de idade, distribuídos em blocos ao acaso em função do sexo, do grau de sangue e do peso ao nascer.

Três tratamentos experimentais foram estudados:

1 - Fornecimento diário de um concentrado com células viáveis $\left(1,9\right.$ x $10^{10} \mathrm{UFC} /$ animal•dia $)$ de Lactobacillus acidophilus (LT 516), do nascimento aos 56 dias de idade;

2 - Fornecimento diário do mesmo concentrado com células viáveis $\left(1,9 \times 10^{10} \mathrm{UFC} / a n i m a l \bullet d i a\right)$ de Lactobacillus acidophilus (LT 516), do nascimento aos 10 dias de idade; e

3 - Controle. Não recebeu Lactobacillus acidophilus.

Nas primeiras horas seguintes ao nascimento, os bezerros permaneceram com as mães para ingestão de colostro, à vontade. Após este período, os bezerros foram conduzidos aos abrigos individuais, a campo, e aqueles dos tratamentos 1 e 2 receberam, já no mesmo dia, colostro adicionado de $100 \mathrm{~mL}$ de leite desnatado reconstituído (LDR), com $12 \%$ de extrato seco desengordurado(ESD), com Lactobacillus acidophilus (LT 516), e os do tratamento 3, apenas colostro.

Os animais receberam 4 litros de colostro/ bezerro $\bullet$ dia durante o $2 \underline{0}$ e $3 \underline{0}$ dia e do $4 \underline{0}$ ao $7 \underline{0}$ dia, 4 litros de leite integral/bezerro•dia metade pela manhã e metade à tarde. A partir do 8 o dia, os animais receberam 4 litros de leite integral/bezerro•dia, em uma só refeição, pela manhã. Os bezerros do tratamento 1 receberam, todos os dias, do nascimento aos 56 dias de idade, $100 \mathrm{~mL}$ de LDR (12\% ESD) contendo LT 516, adicionado ao leite; os do tratamento 2 receberam este tratamento até aos 10 dias de idade e os 
Rev. bras. zootec.

do tratamento 3 não receberam LT 516. O desaleitamento de todos os bezerros foi realizado, abruptamente, aos 56 dias de idade.

A composição média do leite integral, observada ao longo do experimento, foi de $12,49 \%$ de extrato seco total, $3,55 \%$ de gordura e $3,17 \%$ de proteína bruta.

O concentrado inicial (60\% de milho grão, $22 \%$ de farelo de soja, $15 \%$ de farelo de trigo, $2 \%$ de calcário calcítico e $1 \%$ de mistura mineral) e capim-elefante (Pennisetum purpureum Schum) verde e picado, cujas composições se encontram na Tabela 1 , ficaram à disposição dos animais, à vontade, a partir do $8^{\circ}$ dia de idade.

O fornecimento de água limpa aos bezerros foi feito a partir do nascimento, sendo renovada duas vezes ao dia.

Efetuaram-se o corte e a desinfecção do umbigo dos animais, quando chegaram nos abrigos individuais. A descorna foi realizada com uso de pasta apropriada, aos 10 dias de idade. Aos 35 dias foram realizados banhos carrapaticida. Os bezerros que apresentaram diarréia não foram medicados.

Amostras semanais de cada alimento foram obtidas para as determinações de matéria seca, proteína bruta, fibra em detergente neutro e fibra em detergente ácido, sendo as duas últimas somente para o concentrado inicial e o volumoso, conforme descrito por AOAC (1984) e SILVA (1990). Os consumos diários de matéria seca, (leite, concentrado e volumoso) foram determinados para cada bezerro, mediante pesagem das quantidades oferecidas e sobras.

Para as determinações da digestibilidade aparente, foram realizadas coleta total de fezes nos machos (21 animais), dos 45 aos 52 dias de idade, com dois dias de adaptação e cinco de coleta de fezes (SILVA e LEÃO, 1979). As amostras diárias de fezes foram homogeneizadas e alíquotas de $10 \%$ foram conservadas em congelador $\left(-15^{\circ} \mathrm{C}\right)$, para formar uma amostra composta, posteriormente submetida às determinações de matéria seca e proteína bruta. Análises dos alimentos fornecidos (leite integral, concentrado e volumoso) e sobras de concentrado e volumoso também foram realizadas.

Os animais foram pesados ao nascer e semanalmente, até o final do período experimental.

Exames diários das fezes foram conduzidos segundo metodologia descrita por LARSON et al. (1977), avaliando-se a aparência física, com escores de 1 a 4 ( 1 = normais, 2 = normais pastosas, $3=$ diarréia e $4=$ diarréia profusa $)$, o odor $(\mathrm{A}=$ normal, $\mathrm{B}=$ ligeiramente ofensivo e $\mathrm{C}=$ altamente ofensivo) e a consistência ( 1 = normal, 2 = espumosa, $3=$ com muco, $4=$ pegajosa e $5=$ um pouco dura).

Aos 10 e 56 dias de idade, amostras de sangue foram coletadas em tubos contendo heparina como anticoagulante, acondicionadas em caixa de isopor contendo gelo e imediatamente transportadas ao Laboratório de Análises da Escola de Medicina da Universidade Federal de Juiz de Fora onde, utilizando-se aparelho PHA 1\2h. Foram realizadas análises de hematócrito (HTC), hemoglobina (Hb), contagem de glóbulos vermelhos (CGV), hemoglobina globular média (HGM), concentração hemoglobínica globular média (CHGM), volume globular médio (VGM) e contagem global de leucócitos (GLOBAL).

Aos 30 dias de idade, todos os animais foram submetidos ao teste de xilose. Após jejum alimentar de 24 horas, os animais receberam, via oral, uma solução de xilose na base de 0,5 grama de xilose por $\mathrm{kg}$ de peso vivo. Coletaram-se amostras de sangue 0 , 30, 60, 90, 120, 150, 180, 240 e 300 minutos após fornecimento da xilose. Durante o período de coleta do sangue, os animais ficaram em jejum hídrico. $\mathrm{Na}$ análise do plasma utilizou-se o método do cloreto de orcinol-férrico (BOLTON et al., 1975).

Amostras de fezes foram coletadas, assepticamente, após massagem retal, nos dias 1, 3, $7,14,21,28,35,42,49$ e 56, para contagem de coliformes totais e lactobacilos facultativos, usando os meios agar MacConkey e Rogosa SL, respectivamente (HIGGINBOTHAM e BATH, 1993). Para plaqueamento foi utilizada a técnica da microgota; as placas em duplicatas, já com agar, foram "divididas"

Tabela 1 - Teores médios de matéria seca (MS), proteína bruta (PB), fibra em detergente neutro (FDN) e fibra em detergente ácido (FDA) do concentrado inicial e do volumoso (capim-elefante, verde e picado) (\%MS)

Table 1 - Average dry matter (DM), crude protein (CP), neutral detergent fiber (NDF) and acid detergent fiber (ADF) content in starter and forage (elephant grass, fresh and choped) (\%DM)

\begin{tabular}{lcc}
\hline $\begin{array}{l}\text { Constituinte } \\
\text { Constituint }\end{array}$ & $\begin{array}{c}\text { Concentrado inicial } \\
\text { Starter }\end{array}$ & $\begin{array}{c}\text { Volumoso } \\
\text { Forage }\end{array}$ \\
\hline MS $(\%)$ & 87,63 & 22,00 \\
$D M$ & 20,12 & 8,07 \\
PB & & \\
$C P$ & 17,25 & 72,59 \\
FDN & & \\
$N D F$ & 6,56 & 44,52 \\
FDA & & \\
$A D F$ & & \\
\hline
\end{tabular}


em três partes e, com auxílio de uma pipeta automática, foram inoculados, em cada, quatro porções de 10 ppm com diluição $10^{-2}$ a $10^{-7}$. As placas com Agar Rogosa SL foram incubadas em microarofilia a $37^{\circ} \mathrm{C}$ por 24 horas e as com agar MacConkey em aerobiose a $37^{\circ} \mathrm{C}$ por 14 horas (PELCZAR et al., 1981). A contagem foi realizada com auxílio de um contador de colônias, considerando microgotas que proporcionaram de 3 a 60 colônias.

Aos 58 dias de idade (48 horas pós-interrupção de fornecimento de Lactobacillus acidophilus aos animais do tratamento 1), os machos (21) foram abatidos. Assepticamente, foram removidas amostras da digesta do duodeno $(30 \mathrm{~cm}$ após a terceira alça intestinal), do jejuno (30 cm anteriormente à região jejuno-íleo) e do íleo (30 cm anteriormente ao óstio ileocecal), para determinação do $\mathrm{pH}$ e contagens de lactobacilos facultativos e de coliformes totais. Segmentos do tubo intestinal $(10 \mathrm{~cm}$ de cada região acima citada) foram removidos para contagens, em nível de mucosa, de lactobacilos facultativos e coliformes totais. As amostras, recém-coletadas, foram acondicionadas em frascos apropriados, colocadas em caixas de isopor contendo gelo e imediatamente enviadas aos laboratórios de análises bromatológicas e microbiológicas da EMBRAPA - Gado de Leite,
Coronel Pacheco, MG, onde foram determinados os valores de $\mathrm{pH}$ e as contagens microbianas utilizando a técnica da microgota, já descrita.

Os dados de consumo, digestibilidade, ganho de peso e parâmetros sangüíneos foram submetidos a análises de variância. Os dados de concentração de xilose foram analisados em parcelas subdivididas, com os tratamentos experimentais nas parcelas e os tempos de coleta nas subparcelas. Posteriormente foram ajustadas equações de regressão para cada tratamento experimental. Números e médias das contagens bacterianas foram convertidos em logaritmos para realização das análises de variância. Para comparação das médias, utilizou-se o teste de Tukey, a 5 e $1 \%$ de probabilidade. Os dados sobre aparência física, odor e consistência das fezes foram analisados pelo teste Qui-quadrado.

\section{Resultados e Discussão}

Não houve diferença entre tratamentos nos consumos e nas digestibilidades aparentes da matéria seca e da proteína bruta, peso vivo ao nascimento e aos 56 dias de idade e ganho de peso médio diário dos bezerros (Tabela 2). CRUYWAGEN et al. (1996), utilizando Lactobacillus acidophilus fornecido dia-

Tabela 2 - Consumo médio e digestibilidade aparente média da matéria seca (MS) e da proteína bruta (PB), peso vivo médio ao nascer e aos 56 dias de idade e ganho de peso médio diário dos bezerros

Table 2 - Average intake and dry matter (DM) crude protein (CP) and apparent digestibility (\%), average live weight $(\mathrm{kg})$ at birth and 56 days of age, and average daily weight gain of the calves

\begin{tabular}{|c|c|c|c|c|}
\hline \multirow[t]{2}{*}{$\begin{array}{l}\text { Variável } \\
\text { Variable }\end{array}$} & \multicolumn{3}{|c|}{$\begin{array}{l}\text { Probiótico } \\
\text { Probiotic }\end{array}$} & \multirow[t]{2}{*}{$\begin{array}{l}\text { EPM }^{1} \\
\text { SEM }\end{array}$} \\
\hline & $56 \mathrm{~d}$ & $\frac{\text { Probiot }}{10 \mathrm{~d}}$ & $\begin{array}{c}\text { Sem } \\
\text { Without }\end{array}$ & \\
\hline \multicolumn{5}{|l|}{ Consumo (g/anim•d) } \\
\hline \multicolumn{5}{|l|}{ Intake } \\
\hline $\mathrm{MS}(D M)$ & 833 & 817 & 877 & 27 \\
\hline$P B(C P)$ & 187 & 185 & 198 & 5 \\
\hline \multicolumn{5}{|l|}{ Digestibilidade aparente (\%) } \\
\hline \multicolumn{5}{|l|}{ Apparent digestibility } \\
\hline MS $(D M)$ & 84,07 & 83,97 & 82,64 & 1,07 \\
\hline$P B(C P)$ & 80,49 & 77,78 & 75,41 & 1,41 \\
\hline \multirow{2}{*}{\multicolumn{5}{|c|}{ Peso corporal $(\mathrm{kg})$}} \\
\hline Bodyweight & & & & \\
\hline $\begin{array}{l}\text { Ao nascer } \\
\text { At birth }\end{array}$ & 34,2 & 34,7 & 35,1 & 0,5 \\
\hline $\begin{array}{l}\text { Aos } 56 \text { dias de idade } \\
\text { At } 56 \text { days of age }\end{array}$ & 65,3 & 63,9 & 67,0 & 1,5 \\
\hline $\begin{array}{l}\text { Ganho de peso }(\mathrm{g} / \mathrm{anim} \bullet \mathrm{d}) \\
\text { Body weight gain }\end{array}$ & 554 & 522 & 570 & \\
\hline
\end{tabular}

Body weight gain

Médias, na linha, não diferem $(P>0,05)$ pelo teste Tukey.

Means, within a row, do not differ $(\mathrm{P}>.05)$ by Tukey test.

1 EPM = Erro-padrão na média.

1 SEM = Standard error of mean. 
riamente a bezerros, também não encontraram diferença para o consumo de matéria seca até as seis semanas de idade, entre animais que receberam probiótico e aqueles do grupo controle. Corah, 1990, citado por MONTES e PUGH (1993), concluiu que os resultados de pesquisa são ainda inconsistentes, quanto aos efeitos do probiótico sobre a digestibilidade aparente de nutrientes.

A literatura sobre a utilização de Lactobacillus acidophilus como probiótico para bezerros é bastante reduzida e inconsistente. Alguns autores observaram melhores desempenhos de bezerros recebendo probiótico (SCHWAB et al., 1980; ROSELL, 1987; ROACH et al., 1989; e ABE et al., 1995), enquanto outros não verificaram diferença entre bezerros tratados e os do grupo controle (MORRILL et al., 1977; ELLINGER et al., 1978; JENNY et al., 1991; MORRILL et al., 1992; HIGGINBOTHAM e BATH, 1993; e ABU et al., 1996). O modo de administração e a qualidade do produto, além das condições do ambiente onde os ensaios são realizados, sem dúvida, podem justificar a diversidade dos resultados obtidos com a utilização de probióticos para bezerros.

Oito, nove e onze animais, dos tratamentos $1,2 \mathrm{e}$ 3 , respectivamente, estavam consumindo mais de 600 g de concentrado por dia aos 56 dias de idade, condição importante para o sucesso do desaleitamento precoce. Os consumos médios diários de concentrado foram, respectivamente, 376,355 e $442 \mathrm{~g}$, para os três tratamentos, semelhantes ao encontrado por SIGNORETTI (1994), entre outros. Em média, o leite integral, o concentrado e o capim-elefante participaram, respectivamente, com 61,57; 35,50; e 2,93\% do consumo total de matéria seca no período estudado.

O fornecimento de Lactobacillus acidophilus teve efeito favorável sobre as fezes dos animais; aqueles que receberam probiótico, tanto por 56 quanto por 10 dias, apresentaram menor $(\mathrm{P}<0,01)$ número de dias com diarréia e diarréia profusa (escores 3 e 4), em comparação aos animais do grupo controle. Somente no grupo controle (sem probiótico) foram observados casos de diarréias profusas (escore 4). No tratamento 1, apenas um animal apresentou diarréia por dois dias. No tratamento 2 , um animal apresentou diarréia por um dia e um segundo animal, por dois dias. Já no tratamento sem probiótico, um animal apresentou dois dias de diarréia e três dias de diarréia profusa; um segundo animal, três dias de diarréia; um terceiro animal, dois dias de diarréia e um dia de diarréia profusa; um quarto animal, dois dias de diarréia; e um quinto animal, três dias de diarréia e três dias de diarréia profusa. Em termos percentuais, as ocorrências de diarréia foram de 8,$3 ; 16,7$; e $41,7 \%$, respectivamente, para os tratamentos 1,2 e 3 . ÁVILA et al. (1995) concluíram que o fornecimento de um probiótico contendo Lactobacillus acidophilus, combinado com uma vacina contendo pili K99 e A14 de Escherichia coli, foi eficiente no controle da diarréia de bezerros.

Nenhum dos bezerros recebendo probiótico (tratamentos 1 e 2) apresentaram fezes sanguinolentas e os casos de diarréia predominaram no início da segunda semana de idade, ocasião em que os animais passaram a receber os 4 litros de leite em uma só refeição. Por outro lado, no grupo controle, três dos cinco animais com diarréia apresentaram sangue nas fezes. Segundo CHARLES e FURLONG (1992), raramente os bezerros com colibacilose, geralmente com uma semana de idade, apresentam fezes com sangue. Fezes escuras e com estrias de sangue são sintomas de salmonelose, que ocorre, em geral, em bezerros mais velhos. No presente trabalho, os casos de diarréia ocorreram em idades diversas, com maior concentração na segunda semana de vida dos bezerros.

Com relação ao odor e à consistência das fezes, não houve diferença entre os tratamentos experimentais. Em termos percentuais, foram observados 16,1; 17,1; e 19,6\% dos dias com odor ligeira ou altamente ofensivo, para os tratamentos 1, 2 e 3, respectivamente. Estas fezes foram geralmente de bezerros diarréicos ou aqueles com até 10 dias de idade. Fezes pegajosas foram mais freqüentes na primeira semana de vida dos bezerros, devido, provavelmente, ao consumo exclusivo de dieta líquida. Os animais controle apresentaram fezes espumosas com mais freqüência, nem sempre relacionadas com diarréias. Apesar de não ter sido estudada a etiologia das diarréias, na maioria das vezes, as fezes dos animais com diarréia apresentavam-se espumosas, muito provavelmente em virtude da produção de gás pelos microrganismos.

Não houve diferença entre tratamentos para nenhum dos parâmetros sangüíneos analisados (Tabela 3). Os resultados obtidos podem ser considerados normais, estando de acordo com a literatura (SCHALM et al., 1975; FERREIRA NETO et al. 1977).

Não houve diferença entre tratamentos para a concentração de xilose no plasma (Tabela 4, Figura 1), o que sugere igual capacidade de absorção deste carboidrato em nível de intestino dos animais, indicando que, provavelmente, o local de absorção no intestino não foi danificado por patógenos, inclusive nos animais que não foram tratados com Lactobacillus 
acidophilus (tratamento 3).

Não houve diferença entre tratamentos nos valores de $\mathrm{pH}$ encontrados na digesta intestinal, 6,68; 6,58 ; e 6,38, mas foi observada diferença $(\mathrm{P}<0,01)$ entre as três regiões do intestino delgado, 5,$87 ; 6,45$; e 7,32, tendo o íleo apresentado o maior $\mathrm{pH}$ e o duodeno, o menor. Smith (1960), citado por LUCCI
(1989), determinou o $\mathrm{pH}$ dos intestinos delgados de bezerros saudáveis, com diarréia moderada e diarréia severa, concluindo que, quanto mais severa a diarréia, menor o valor de $\mathrm{pH}$. Apesar da diferença provavelmente existente entre as condições dos experimentos, verifica-se que houve tendência de menores valores de $\mathrm{pH}$ para os animais que não rece-

Tabela 3 - Valores médios de hematócrito (HTC), hemoglobina $(\mathrm{Hb})$, contagem de glóbulos vermelhos (CGV), hemoglobina globular média (HGM), concentração hemoglobínica globular média (CHGM), volume globular médio (VGM) e contagem global de leucócitos (GLOBAL), analisados aos 10 e 56 dias de idade dos bezerros

Table 3 - Average values of hematocrit (HTC), hemoglobin (Hb), red globules count (RGC), globular hemoglobin $(G H)$, hemoglobin concentration (GHC), globular volume (GV) and leukocytes global count (GLOBAL), analyzed at 10 and 56 days of age of calves

\begin{tabular}{|c|c|c|c|c|c|c|c|}
\hline & \multicolumn{6}{|c|}{$\begin{array}{l}\text { Probiótico } \\
\text { Probiotic }\end{array}$} & \multirow[t]{3}{*}{$\begin{array}{c}\text { Valores normais } 1 \\
\text { Normal values }\end{array}$} \\
\hline & \multicolumn{2}{|c|}{56 dias } & \multicolumn{2}{|c|}{10 dias } & \multicolumn{2}{|c|}{ Sem (Without) } & \\
\hline & 10 dias & 56 dias & 10 dias & 56 dias & 10 dias & 56 dias & \\
\hline $\operatorname{HTC}(\%)$ & 37,86 & 28,99 & 37,56 & 31,45 & 37,10 & 28,96 & $30-40$ \\
\hline $\begin{array}{l}H T C \\
\mathrm{Hb}(\mathrm{g} \%)\end{array}$ & & & & & & & \\
\hline CGV $\left(X 10^{6} / \mu \mathrm{L}\right)$ & $\begin{array}{l}11,93 \\
8,16\end{array}$ & 10,40 & 13,81 & $10, / 6$ & 11,99 & 10,64 & $8-14$ \\
\hline$R G C$ & 8,16 & 7,29 & 8,37 & 7,82 & 8,44 & 7,47 & 9,04 \\
\hline $\begin{array}{l}\operatorname{HGM}(\mathrm{pg}) \\
G H\end{array}$ & 14,78 & 14,22 & 14,18 & 13,93 & 13,18 & 14,37 & $14,4-18,6$ \\
\hline $\begin{array}{l}\mathrm{CHGM}(\%) \\
G H C\end{array}$ & 31,69 & 34,91 & 31,47 & 34,44 & 32,28 & 37,84 & $26-34$ \\
\hline $\begin{array}{l}\operatorname{VGM}\left(\mu^{3}\right) \\
G V\end{array}$ & 43,91 & 40,00 & 45,05 & 39,78 & 44,39 & 38,22 & $40-60$ \\
\hline $\operatorname{GLOBAL}(\mu \mathrm{L})$ & 11025 & 12816 & 11658 & 13358 & 11483 & 12116 & $4000-12000$ \\
\hline
\end{tabular}

${ }^{1}$ Valores normais segundo SCHALM et al. (1975) e FERREIRA NETO et al. (1977).

${ }^{1}$ Normal values according to SCHALM et al. (1975) and FERREIRA NETO et al. (1977).

Tabela 4 - Concentração média de xilose no plasma sangüíneo dos bezerros, em função do tempo (horas), após o fornecimento da solução de xilose

Table 4 - Average blood plasma xylose concentration, according to time (hours) after xylose solution ingestion by calves

\begin{tabular}{lccc}
\hline \begin{tabular}{l} 
Tempo após fornecimento $\begin{array}{l}\text { (horas) } \\
\text { Time after ingestion } \\
\text { (hours) }\end{array}$ \\
\cline { 2 - 4 }
\end{tabular} & \multicolumn{3}{c}{$\begin{array}{c}\text { mg de xilose/100mL de plasma } \\
\text { mg of xylose/100 mL of plasma }\end{array}$} \\
\cline { 2 - 4 } 0 & 56 dias & Probiótico(Probiotic) \\
0,5 & 9,38 & 10 dias & Sem(Without) \\
1,0 & 24,39 & 9,33 & 10,41 \\
1,5 & 38,14 & 21,17 & 24,44 \\
2,0 & 46,27 & 30,95 & 38,22 \\
2,5 & 51,47 & 44,87 & 47,98 \\
3,0 & 51,37 & 51,11 & 50,23 \\
4,0 & 49,45 & 52,53 & 53,75 \\
5,0 & 45,64 & 51,29 & 52,40 \\
\hline Média & 43,98 & 47,02 & 48,15 \\
Mean & 40,01 & 42,62 & 40,92 \\
\hline
\end{tabular}

Médias, na linha, não diferem $(P>0,05)$ pelo teste Tukey.

Means, within a row, do not differ $(\mathrm{P}>.05)$ by Tukey test. 


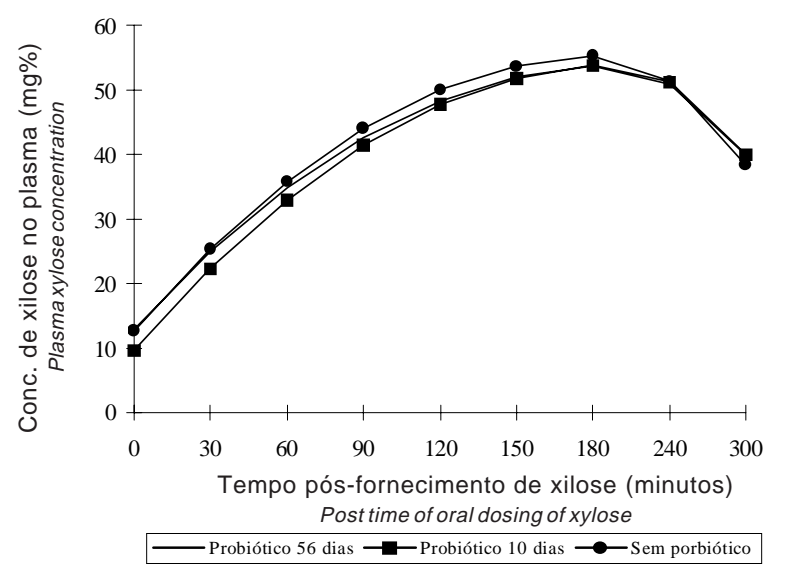

Figura 1 - Concentações médias de xilose no plasma sangüíneo em relaçõa ao tempo, em minutos pós-fornecimento oral de xilose.

Figure 1 - Average xilose concentrations in the blood plasma on post time, of oral dosing of xilose.

beram probiótico, que apresentaram maior $(\mathrm{P}<0,01)$ número de dias com diarréia.

Os animais que receberam probiótico nos 10 primeiros dias de idade apresentaram maior número de lactobacilos facultativos no intestino delgado, sendo os tratamentos 1 e controle menores e semelhantes (Tabela 5). GILLILAND et al. (1980), comparando duas estirpes de Lactobacillus acidophilus em bezerros, não encontraram, aos 10 dias de idade, diferença entre estirpes e em relação ao controle, no número de lactobacilos facultativos presentes na digesta do intestino delgado.

O maior número de lactobacilos facultativos nos intestinos delgados dos animais do tratamento 2 sugere que a interrupção do fornecimento de Lactobacillus acidophilus aos 10 dias de idade fez com que houvesse maior implantação e reprodução deste microrganismo no intestino delgado, o que não ocorreu com os animais do tratamento 1, em que o fornecimento de Lactobacillus acidophilus foi diário e contínuo até os 56 dias de idade, e com os do tratamento 3, que não receberam Lactobacillus acidophilus.

Em relação aos locais pesquisados (Tabela 5), a digesta do íleo apresentou maior número de lactobacilos facultativos $(\mathrm{P}<0,01)$ em relação à digesta do duodeno, não diferindo, no entanto, da digesta do jejuno. A mucosa do duodeno apresentou menor número de lactobacilos facultativos $(\mathrm{P}<0,01)$ que a mucosa do íleo -não diferindo também da mucosa do jejuno. KRAUSE et al. (1995), trabalhando com o efeito da dieta na aderência de lactobacilos no trato gastrointestinal de suínos, relataram que o número deste microrganismo ao longo do trato gastrointestinal é maior, devido às características das secrecões gastrointestinais, dos movimentos peristálticos e da movimentação da digesta rumo à porção final deste.

Os animais do tratamento 3 (controle) apresentaram maior número de coliformes totais no intestino delgado $(\mathrm{P}<0,01)$, enquanto os que receberam Lactobacillus acidophilus até 56 dias, menor número. Em relação aos locais pesquisados, a digesta do íleo apresentou maior $(\mathrm{P}<0,01)$ número de coliformes totais e a mucosa do duodeno, menor (Tabela 6). Segundo Ingram (1962), citado por LUCCI (1989), no duodeno os coliformes atingem o pico entre 1 e 4 dias de vida e, em bezerros saudáveis, declinam para pequeno número - aproximadamente 10 dias (10 a $10^{2}$ células/mL de digesta), devido à predominância, neste local, dos Lactobacillus sp. Em contraste, animais que morreram por colibacilose apresentaram contagens de Escherichia coli de $10^{7}$ a $10^{8}$ células $/ \mathrm{ml}$ de digesta do duodeno.

Segundo MONTES e PUGH (1993), entre os atributos das bactérias probióticas, está a capacidade de se implantarem no trato gastrintestinal e eficientemente inibirem patogênicos. Sinha (1979), citado por SHAHANI e AYEBO (1980), alimentando ratos com leite não fermentado contendo Lactobacillus acidophilus, observou aumento na contagem de lactobacilos e concomitante decréscimo no número de coliformes no intestino. MURALIDHARA et al. (1977), trabalhando com Lactobacillus lactis para suínos, concluíram que a administração deste probiótico aumentou o número de lactobacilos no intestino e diminuiu a contagem de Escherichia coli.

Não houve diferença entre tratamentos no número fecal de lactobacilos facultativos (Tabela 7), entre os quais está o Lactobacillus acidophilus. Aos 7, 14 e 28 dias de idade, houve diferença $(\mathrm{P}<0,05)$ no número de lactobacilos facultativos, tendo as fezes dos animais do tratamento 1 apresentado maior número em relação ao tratamento controle. Pelas médias das contagens $2,73 \times 10^{8}, 2,00 \times 10^{8}$ e $1,21 \times 10^{8}$ UFC/grama de fezes, respectivamente, para os tratamentos 1,2 e 3, pode-se observar superioridade de 36,5 e $125,6 \%$ a favor do tratamento 1, quando comparados aos tratamentos 2 e 3 , respectivamente.

Comparando duas estirpes de Lactobacillus acidophilus como probiótico para bezerros jovens, 
Tabela 5 - Logaritmo das médias das contagens de lactobacilos facultativos na digesta intestinal e em nível de mucosa intestinal

Table 5 - Logarithm of the average facultative lactobacilli counts in intestinal digest (CFU/g of digest) and at intestinal mucosa level (UFC/g of rests of digesta and mucosa fragments)

\begin{tabular}{|c|c|c|c|c|}
\hline \multirow[t]{2}{*}{ Local } & \multicolumn{3}{|c|}{ Probiótico (Probiotic) } & \multirow{2}{*}{$\begin{array}{l}\text { Média } \\
\text { Mean }\end{array}$} \\
\hline & 56 dias & 10 dias & Sem próbiotico & \\
\hline Digesta do duodeno & 3,87 & 5,57 & 3,65 & $4,36^{\mathrm{bc}}$ \\
\hline Digest in duodenum & & & & \\
\hline $\begin{array}{l}\text { Digesta do jejuno } \\
\text { Digest in jejunum }\end{array}$ & 3,92 & 5,61 & 4,02 & $4,52^{\mathrm{ab}}$ \\
\hline $\begin{array}{l}\text { Digesta do íleo } \\
\text { Digest in illeum }\end{array}$ & 4,38 & 6,40 & 4,82 & $5,21^{\mathrm{a}}$ \\
\hline $\begin{array}{l}\text { Mucosa do duodeno } \\
\text { Mucosa of duodenum }\end{array}$ & 3,33 & 4,36 & 2,57 & $3,42^{\mathrm{d}}$ \\
\hline $\begin{array}{l}\text { Mucosa do jejuno } \\
\text { Mucosa of jejunum }\end{array}$ & 2,75 & 4,38 & 3,49 & $3,54^{\mathrm{cd}}$ \\
\hline $\begin{array}{l}\text { Mucosa do íleo } \\
\text { Mucosa of illeum }\end{array}$ & 3,72 & 5,21 & 3,86 & $4,26^{\mathrm{bc}}$ \\
\hline $\begin{array}{l}\text { Média } \\
\text { Mean }\end{array}$ & $3,66^{\mathrm{B}}$ & $5,26^{\mathrm{A}}$ & $3,74^{\mathrm{B}}$ & \\
\hline
\end{tabular}

Tabela 6 - Efeito dos tratamentos sobre o logaritmo das médias das contagens de coliformes totais na digesta intestinal e em nível de mucosa intestinal

Table 6 - Effect of treatments on the logarithm of the average coliform counts in intestinal digest and at intestinal mucosa level

\begin{tabular}{|c|c|c|c|c|}
\hline \multirow[t]{2}{*}{ Local } & \multicolumn{3}{|c|}{ Probiótico (Probiotic) } & \multirow{2}{*}{$\begin{array}{l}\text { Média } \\
\text { Mean }\end{array}$} \\
\hline & 56 dias & 10 dias & Sem próbiotico & \\
\hline Digesta do duodeno & 3,39 & 3,85 & 4,12 & \\
\hline Digest in duodenum & & & & \\
\hline $\begin{array}{l}\text { Digesta do jejuno } \\
\text { Digest in jejunum }\end{array}$ & 4,13 & 4,36 & 4,74 & $4,41^{\mathrm{c}}$ \\
\hline $\begin{array}{l}\text { Digesta do íleo } \\
\text { Digest in illeum }\end{array}$ & 5,61 & 6,18 & 6,30 & $6,03^{\mathrm{a}}$ \\
\hline $\begin{array}{l}\text { Mucosa do duodeno } \\
\text { Mucosa of duodenum }\end{array}$ & 2,73 & 3,06 & 3,45 & $3,08^{\mathrm{f}}$ \\
\hline $\begin{array}{l}\text { Mucosa do jejuno } \\
\text { Mucosa of jejunum }\end{array}$ & 3,07 & 3,44 & 3,69 & $3,40^{\mathrm{e}}$ \\
\hline $\begin{array}{l}\text { Mucosa do íleo } \\
\text { Mucosa of illeum }\end{array}$ & 4,59 & 5,02 & 5,58 & $5,06^{\mathrm{b}}$ \\
\hline $\begin{array}{l}\text { Média } \\
\text { Mean }\end{array}$ & $3,92^{\mathrm{C}}$ & $4,32^{\mathrm{B}}$ & $4,65^{\mathrm{A}}$ & \\
\hline
\end{tabular}

Médias, na linha/coluna, seguidas de letras maiúsculas e minúsculas diferentes são diferentes $(P<0,01)$ pelo teste Tukey. Means, within a row/column, followed by different small and capital letters are different $(P<.01)$ by Tukey test.

durante 14 dias, GILLILAND et al. (1980) não encontraram diferença entre eles, ou em relação ao controle, quanto à contagem fecal de lactobacilos facultativos.

Não houve diferença entre tratamentos no número de coliformes totais nas fezes dos bezerros (Tabela 8); apenas aos 35 dias de idade, os animais do tratamento controle apresentaram maior número $(\mathrm{P}<0,05)$ de coliformes totais em relação ao tratamento 1 . O aumento do número de lactobacilos na flora intestinal, acompanhado pela concomitante redução no número de coliformes, é aparentemente normal no desenvolvimento da flora intestinal de bezerros (GILLILAND et al., 1980). Estudos com galinhas, suínos e bezerros têm mostrado significativa diminuição na excreção fecal de coliformes patogênicos e concomitantemente melhora na saúde e performance com a suplementação com lactobacilos (Tortuero, 1973; Moon, 1975; e Bruce et al., 1979, citados por ZINN e SHEN, 1994). 
Rev. bras. zootec.

Tabela 7 - Efeito dos tratamentos experimentais sobre o logaritmo das médias das contagens de lactobacilos facultativos (UFC/grama de fezes), em função da idade dos bezerros (dias)

Table 7 - Treatment effect on the logaritmic of the average facultative lactobacilli counts in feces (CFU/g of feces), according to calves age (days)

\begin{tabular}{lccc}
\hline Idade (dias) & \multicolumn{3}{c}{ Probiótico } \\
\cline { 2 - 4 } 1 & 56 dias $)$ & 10 dias & Sem \\
\hline 3 & $4,73^{\mathrm{a}}$ & $5,19^{\mathrm{a}}$ & $5,60^{\mathrm{a}}$ \\
7 & $7,50^{\mathrm{a}}$ & $7,25^{\mathrm{a}}$ & $7,46^{\mathrm{a}}$ \\
14 & $8,59^{\mathrm{a}}$ & $8,05^{\mathrm{ab}}$ & $7,95^{\mathrm{b}}$ \\
21 & $8,54^{\mathrm{a}}$ & $8,13^{\mathrm{ab}}$ & $7,65^{\mathrm{b}}$ \\
28 & $7,84^{\mathrm{a}}$ & $8,03^{\mathrm{a}}$ & $7,99^{\mathrm{a}}$ \\
35 & $8,14^{\mathrm{a}}$ & $7,93^{\mathrm{ab}}$ & $7,51^{\mathrm{b}}$ \\
42 & $7,83^{\mathrm{a}}$ & $8,09^{\mathrm{a}}$ & $8,00^{\mathrm{a}}$ \\
49 & $7,80^{\mathrm{a}}$ & $8,08^{\mathrm{a}}$ & $7,76^{\mathrm{a}}$ \\
56 & $7,34^{\mathrm{a}}$ & $7,62^{\mathrm{a}}$ & $7,52^{\mathrm{a}}$ \\
\hline Média & $7,30^{\mathrm{a}}$ & $7,98^{\mathrm{a}}$ & $7,35^{\mathrm{a}}$ \\
Mean & $7,56^{\mathrm{a}}$ & $7,64^{\mathrm{a}}$ & $7,48^{\mathrm{a}}$ \\
\hline
\end{tabular}

Médias, na linha, diferentes letras são diferentes $(P<0,05)$ pelo teste Tukey.

Means, within a row, followed by differents letters are different $(\mathrm{P}<.05)$ by the Tukey test.

Tabela 8 - Efeito dos tratamentos experimentais sobre o logaritmo das médias das contagens de coliformes nas fezes (UFC/grama de fezes), em função da idade dos bezerros (dias)

Table 8 - Treatment effect on the logaritmic of the average coliform counts in feces(CFU/g of feces), according to calves age (days)

\begin{tabular}{lccc}
\hline Idade (dias) & \multicolumn{3}{c}{ Probiótico } \\
\cline { 2 - 4 } Age (days) & 56 dias & 10 dias & Sem \\
\hline 1 & $5,97^{\mathrm{a}}$ & $6,21^{\mathrm{a}}$ & $6,80^{\mathrm{a}}$ \\
3 & $8,97^{\mathrm{a}}$ & $8,96^{\mathrm{a}}$ & $9,04^{\mathrm{a}}$ \\
7 & $8,13^{\mathrm{a}}$ & $8,27^{\mathrm{a}}$ & $8,23^{\mathrm{a}}$ \\
14 & $7,39^{\mathrm{a}}$ & $7,77^{\mathrm{a}}$ & $7,80^{\mathrm{a}}$ \\
21 & $7,46^{\mathrm{a}}$ & $7,70^{\mathrm{a}}$ & $8,51^{\mathrm{a}}$ \\
28 & $7,06^{\mathrm{a}}$ & $7,26^{\mathrm{a}}$ & $7,89^{\mathrm{a}}$ \\
35 & $6,83^{\mathrm{b}}$ & $7,60^{\mathrm{ab}}$ & $8,16^{\mathrm{a}}$ \\
42 & $6,77^{\mathrm{a}}$ & $6,85^{\mathrm{a}}$ & $7,15^{\mathrm{a}}$ \\
49 & $6,32^{\mathrm{a}}$ & $7,08^{\mathrm{a}}$ & $7,11^{\mathrm{a}}$ \\
56 & $6,72^{\mathrm{a}}$ & $6,75^{\mathrm{a}}$ & $7,31^{\mathrm{a}}$ \\
\hline Média & $7,16^{\mathrm{a}}$ & $7,45^{\mathrm{a}}$ & $7,80^{\mathrm{a}}$
\end{tabular}

Mean

Médias, na linha, diferentes letras são diferentes $(P<0,05)$ pelo teste Tukey.

Means, within a row, followed by differents letters are different $(\mathrm{P}<.05)$ by the Tukey test.

O fornecimento de células viáveis de Lactobacillus acidophilus a bezerros de rebanhos leiteiros jovens tem mostrado redução na incidência de diarréias (BECHMAN et al., 1977) e aumento no número de lactobacilos e concomitante redução de coliformes nas fezes (Bruce et al., 1979, citados por SISSONS, 1989). Entretanto, existem trabalhos que não têm mostrado estes benefícios (HATCH et al., 1973; ELLINGER et al., 1978).

\section{Conclusões}

Nas condições deste experimento, conclui-se que o fornecimento de probiótico à base da estirpe LT 516 de Lactobacillus acidophilus, isolada a partir de fezes de bezerros, não influenciou significativamente os consumos e as digestibilidades aparentes de matéria seca e da proteína bruta, o ganho de peso dos bezerros, os números de hematócrito, hemoglobina, 
glóbulos vermelhos e hemoglobina globular média, a concentração hemoglobínica globular média, o volume globularmédio, a contagem global de leucócitos, o pH da digesta do intestino delgado, a capacidade absortiva do intestino, avaliada pelo teste da xilose, e a contagem de lactobacilos facultativos e coliformes totais nas fezes desses animais.

Quanto às características das fezes, os bezerros que receberam probiótico tiveram menor ocorrência de diarréia, quando comparados aos do grupo controle, e o fornecimento de probiótico não influenciou as características de odor e consistência das fezes.

Houve diferença entre tratamentos na contagem de lactobacilos facultativos, sendo que os animais que receberam probiótico por dez dias apresentaram maior número destes microrganismos no intestino delgado. O número de coliformes totais no intestino delgado foi maior nos animais controle e menor nos que receberam probiótico por 56 dias.

\section{Referências Bibliográficas}

ABE, F., ISHIBASHI, N., SHINAMURA, S. 1995. Effect of administration of bifidobacteria and lactic acid bacteria to newborn calves and piglets. J. Dairy Sci., 78(12): 2838-2846.

ABU-TARBOUSH, H.M., AL-SAIADY, M.Y., KEIR-EL-NIN, A.H. 1996. Evaluation of diet containing lactobacilli on performance, fecal coliform, and lactobacilli of young dairy calves. Anim. Feed Sci. Techn.., 57(1-2):39-49.

ASSOCIATION OF OFFICIAL ANALYTICAL CHEMISTS AOAC. 1984. Official Methods of the Association of Official Analytical Chemists. 14 ed. Virginia. 1141p.

ÀVILA, F.A., PAULILLO, A.C., SCHOCKEN-ITURRINO, R.P. et al. 1995. A comparative study on the eficiency of a probiotic and the anti-K99 and anti-A14 vaccines in the control of diarrhea in calves in Brazil. Revue d'Elevage et de Medecine Veterinaire des Pays Tropicaus., 48(3):239-243.

BECHMAN, T.J., CHAMBERS, J.V., CUNNINGHAM, M. D. 1977. Influence of Lactobacillus acidophilus on performance of yong dairy calves. J. Dairy Sci., 60(1):74-79.

BOLTON, J.R., MERRITT, A.V., CIMPRICH, R.F. et al. 1975. Normal and abnormal xylose absorption in the horse. School of Vet. Med., University of Pennsilvania, August, p. 183-197.

CHARLES, T.P., FURLONG, J. 1992. Diarréia dos bezerros. Coronel Pacheco: EMBRAPA - CNPGL, 107p.

COSTA, R.R., SANTOS, E.R., ANDRADE, M.A. et al. 1979. Freqüência e causa de doenças do aparelho digestivo em bezerros na bacia leiteira de Goiânia. Anais Esc. Agron. Vet., 9:108-112.

CRUYWAGEN, C.W., JORDAAN, I.N.A, VENTER, L. 1996. Effect of Lactobacillus acidophilus suplementation of milk replacer on preweaning performance of calves. J. Dairy Sci., 79:483-486.

ELliNGER, D.K., MULlER, L.D., GLANTZ, P.J. 1978. Influence of feeding fermented colostrum and Lactobacillus acidophilus on fecal flora and selected blood parameters of young dairy calves. J. Dairy Sci., 61(suppl.1):126.
FERREIRA NETO, J.M.F., VIANA, E.S., MAGALHÃES, L. M. 1977. Patologia Clínica Veterinária. Belo Horizonte: Rabelo Brasil. 279p.

GILLILAND, S.E., BRUCE, L.J., BUSH, L.J. et al., 1980. Comparison of two strains of 74-as dietary adjuncts for young calves. J. Dairy Sci., 63:964-972.

HATCH, R.C., THOMAS, R.O., THAYNE, W.V. 1973. Effect on adding Lactobacillus acidophilus to milk fed to baby calves. J. Dairy Sci., 56:682-691.

HIGGINBOTHAM, G.E., BATH, D.L. 1993. Evaluation of Lactobacillus fermentation cultures in calf feeding systems. J. Dairy Sci., 76:615-620.

JENNY, B.F., VANDIJK, H.J., COLlinS, J.A. 1991. Performance and fecal flora of calves fed Bacillus subtilis concentrate. J. Dairy Sci., 74:1968-1973.

KRAUSE, D.O., EASTER, R.A., WHITE, B.A. 1995. Effect of weaning diet on the ecology of adherent lactobacilli in the gastrointestinal tract of the pig. J. Dairy Sci., 73: 2347-2354.

LARSON, L.L., QWEN, F.G., ALBRIGHT, J.L. et al. 1977. Guidelines toward more uniformity in measuring and reporting calf experimental data. J. Dairy Sci., 60:989-991.

LUCCI, C. S. 1989. Bovinos Leiteiro Jovens: Nutrição - Manejo - Doenças. São Paulo: Ed. Nobel. 317p.

MADRUGA, C.R. SCHENK, M. A.A., GOMES, A. et al. Identificação das principais causas de morbidade e mortalidade de bezerros. In: CONGRESSO BRASILEIRO DE MEDICINA VETERINÁRIA, 19, 1982, Camboriú. Anais...Camboriú, p.39, 1982.

MONTES, A. J., PUGH, D. G. 1993. The use of probiotics in food-animal practice. Vet. Med., 88: 282-288.

MORRILL, J.L., DAYTON, A.D., MICKELSEN, R. 1977. Cultured milk and antibiotics for young calves. J. Dairy Sci., 60:1105-1112.

MORRILL, J.L., LASTER, J.F., MORRILL, J., M. et al. 1992. Plasma protein and probiotic as milk replacer ingredients. $J$. Dairy Sci., 75:267 (Suppl.1).

MURADHARA, K.S., SHEGGEBY, G.G., ELLIKER, P.R. et al. 1977. Effect of feeding Lactobacilli on coliform and Lactobacillus flora of intestinal tissue and feces from piglets. J. Food Protect., 40:288.

PELCZAR, M. J., REID, R., CHAN, E. C. S. 1981. Microbiologia. São Paulo: Ed. Mcgraw. v.2. 1072p.

PENHA, A.M., D‘APICE, N. 1944. Observações sobre a enterite infecciosa dos bezerros. Rev. Soc. Paul. Med. Vet., 6:154-160.

PIANTA, C. 1993. Diarréia neonatal de origem bacteriana em bovinos. Ciência Rural, 23:107-115.

RIBEIRO, M.F.B., SALCEDO, J.H.P., FARIA, J.E. 1983. Inquérito de opinião com criadores da "Zona da Mata" do Estado de Minas Gerais. Arq. Bras. Med. Vet. Zootec., 35:547-556.

ROACH, J., BRINGE, A., AIMUTIS, W.R. 1989. Use of directfed microbials to improve replacer calves performance. $J$. Dairy Sci., 72 (suppl.1):447.

ROSELL, V. 1987. Acidification and probiotics in spanish pig and calf rearing. In: LYONS, T. P. Biotechnology in the feed industry. Nicholasville: Alltech Technical Publications, p.177-180.

SCHALM, O.W., JAIN, N.C., CARROLL, E.J. 1975. Veterinary hematology, 3. ed., Philadelphia: Lea e Febiger. 807p.

SCHWAB, C.G., MOORE, J.J., HOYT, P.M. et al. 1980. Performance and fecal flora of calves fed a nonviable Lactobacillus bulgaricus fermentation production. J. Dairy Sci., 66:1412.

SHAHANI, K.M., AYEBO, A.D. 1980. Role of dietary lactobacilli in gastrointestinal microecology. Amer. J. Clin. Nut., 33: 
Rev. bras. zootec.

2448-2457.

SIGNORETTI, R.D. Substituição do milho e do farelo de soja pelofarelo de gérmen de milho na ração de bezerros desaleitados precocemente. Viçosa, MG: UFV, 1994, 117p. Disserta;cão (Mestrado em Zootecnia) - Universidade Federal de Viçosa, 1994.

SILVA, D.J. 1990. Análise de alimentos (Métodos químicos e biológicos). Viçosa, M.G., Imprensa Universitária - UFV. 165p.

SILVA, J.F.C., LEÃO, M.I. 1979. Fundamentos de Nutrição de Ruminantes. Piracicaba: Livro Ceres. 384p.

SISSONS, J.W. 1989. Potential of probiotic organisms to prevent diarrhoea and promote digestion in farm animals - A review. J. Sci. Food Agric., 49:1-13.

TORRES, A.J.A. Influência de alguns fatores na mortalidade de bezerros em Viçosa (MG), Viçosa, MG: UFV, 1959. 63p. Tese (Mestrado em Zootecnia) - Universidade Federal de Viçosa, 1959.

VALENTE, F.A.T., AMARAL, L.B.S. 1971. Ocorrência de molestias nos rebanhos bovinos do Estado de São Paulo no triênio 65/67. Paratifo nas regiões de Ribeirão Preto e Campinas. O Biológico, 37:306-311.

VANBELLE, M., TELLER, E., FOCANT, M. 1990. Probiotics in animal nutrition: a review. Arch. Anim. Nutr., 40: 543-567.

ZINN, R.A., SHEN, Y. Probiotics in diets for feedlot cattle In: SIMPÓSIO LATINO AMERICANO DE NUTRIÇÃO ANIMAL E SEMINÁRIO SOBRE TECNOLOGIA DA PRODUÇÃO DE RAÇÕES, 1994, Campinas. Anais... Campinas: CBNA, 1994. p.185-196.

Recebido em: 04/12/97

Aceito em: 25/03/99 